\title{
Fat accumulation in adipose tissues as a risk factor for the development of endometrial cancer
}

\author{
KEIICHIRO NAKAMURA, ATSUSHI HONGO, JUNICHI KODAMA and YUJI HIRAMATSU
}

\author{
Departments of Obstetrics and Gynecology, Okayama University Graduate School \\ of Medicine, Dentistry and Pharmaceutical Sciences, Okayama, Japan
}

Received December 28, 2010; Accepted February 18, 2011

DOI: $10.3892 /$ or.2011.1259

\begin{abstract}
Fat accumulation in adipose tissues is a risk factor for the development of human cancers. However, there are no studies describing the fat accumulation in adipose tissue or its distribution in human endometrial cancer. We first examined fat accumulation in adipose tissues separately on CT images of 122 patients with endometrial cancer, and investigated the correlation of these findings with various histological types of endometrial cancers. Fat accumulation in adipose tissues [subcutaneous fat area (SFA) and/or visceral fat areas (VFA)] was strongly correlated with the group of obesity-related biological parameters (weight, body mass index (BMI), waist and body surface area (BSA)) in endometrial cancer. The incidence of type I endometrial cancer was more closely correlated with an increase in obesity-related parameters such as weight $(\mathrm{p}=0.011)$, BMI $(\mathrm{p}=0.006)$, waist circumference $(\mathrm{p}=0.038)$, BSA $(\mathrm{p}=0.016)$, SFA $(\mathrm{p}=0.005)$, total fat area $(\mathrm{TFA})(\mathrm{p}=0.006)$ and total cholesterol (T.Cho) $(\mathrm{P}=0.010)$ than type II endometrial cancer. In particular, the SFA was most strongly correlated with obesity-related biological parameters of type I endometrial cancer. The present findings indicate that type I endometrial cancer has a statistically significant increase in obesity-related biological parameters than type II endometrial cancer. We propose that the subcutaneous fat accumulation in adipose tissue is a strong risk factor for developing type I endometrial cancer.
\end{abstract}

\section{Introduction}

Endometrial cancer is the most common gynecologic malignancy in the world. The association between obesity

Correspondence to: Dr Keiichiro Nakamura, Department of Obstetrics and Gynecology, Okayama University Graduate School of Medicine, Dentistry and Pharmaceutical Sciences, 2-5-1 Shikata-cho, Okayama 700-8558, Japan

E-mail: k-nakamu@cc.okayama-u.ac.jp

Abbreviations: SFA, subcutaneous fat area; VFA, visceral fat areas; TFA, total fat area; BMI, body mass index; BSA, and body surface area; T.Cho, total cholesterol

Key words: endometrial cancer, abdominal obesity, fat accumulation in adipose tissues and increased endometrial cancer risk has been consistently demonstrated in a number of epidemiological studies. Body mass index $(\mathrm{BMI}) \geq 30 \mathrm{~kg} / \mathrm{m}^{2}$, is associated with a 1.7 - to 4.5-fold increase endometrial cancer in risk in Europe and the United States $(1,2)$.

For all stages of endometrial cancer taken together, the overall 5-year survival rate is $\sim 80 \%$. However, there is a substantial prognostic difference between the histological types of endometrial cancers. Type I endometrial cancer represents the majority of endometrial cancer cases, is estrogen-related, usually arises under conditions of endometrial hyperplasia, and tends to be biologically less aggressive (3). Type II endometrial cancer, high-grade, predominantly serous papillary carcinoma, and clear cell carcinoma, are at high risk of relapse and metastatic disease (4).

In Japan, endometrial cancer is currently the third most common gynecologic malignancy in women, with an estimated incidence of 5,398 new cases in 2008 (5). The incidence of endometrial cancer has increased markedly in recent years along with an increase in sedentary lifestyles. The percentage of the Japanese population with a BMI between 25 and $30 \mathrm{~kg} / \mathrm{m}^{2}$ exceeds $20 \%$, and the percentage of people in Japan with a BMI $>30 \mathrm{~kg} / \mathrm{m}^{2}$ is $\sim 3 \%$ (6). In contrast, $10-20 \%$ of the population of Europe and the United States has a BMI $>30 \mathrm{~kg} / \mathrm{m}^{2}$ (7). Thus, although the World Health Organization defines obesity as those people with a BMI $>30 \mathrm{~kg} / \mathrm{m}^{2}$, Japanese criteria define it as a BMI $>25 \mathrm{~kg} / \mathrm{m}^{2}$ (8). Recent epidemiological studies have revealed that the incidence of obesity-related diseases such as diabetes mellitus, hypertension, and hyperlipidemia is significantly greater among Japanese with BMI $>25 \mathrm{~kg} / \mathrm{m}^{2}$ (9).

Obesity is manifested as a markedly high volume of adipose tissue. Recent studies have demonstrated that adipocytes produce a variety of secretory peptides, named adipokines. More recently, some adipokines, such as leptin and adiponectin, have been shown to critically regulate the biological behavior of malignant cells, raising the possibility that adipocytes may have positive roles in the development of malignant diseases through the secretion of adipokines in an endocrine or intracrine manner $(10,11)$. It has been suggested that the biochemical characteristics of visceral and subcutaneous adipose tissues are somewhat different (12). Various epidemiological and experimental data suggest that the clinical significance of fat accumulation in visceral adipose tissues is a risk factor for developing colorectal cancer. 
Giovannucci et al have shown the risk of colorectal cancer in males is related to not only BMI but also to waist-to-hip ratio, which is a surrogate measurement for the fat accumulation in visceral adipose tissue (13). Schoen et al reported that BMI was not statistically significantly associated with colorectal cancer incidence, but waist circumference was for the highest quartile when compared to the lowest quartile (14). Based on these studies, it is reasonable to assume that the degree of the fat accumulation in visceral adipose tissue as well as BMI might be an important factor determining the risk of colorectal cancer development. However, there are no studies describing adipose tissue or its distribution in endometrial cancer.

In this study, we first measured the fat accumulation in visceral and subcutaneous adipose tissues separately on CT images of patients with endometrial cancer, and investigated the relationship of these findings with various histological types of endometrial cancers.

\section{Materials and methods}

Patients. The patient population consisted of 122 patients presenting with International Federation of Gynecology and Obstetrics (FIGO) stage IA-IVB endometrial cancers, including Diabetic status of 12 patients. Each of these patients underwent a total abdominal hysterectomy, bilateral salpingooophorectomy, omentectomy with or without pelvic and/or para-aortic lymphadenectomy at the Department of Obstetrics and Gynecology of Okayama University Hospital. The histological cell types were classified according to the WHO classification as follows: 61 endometrioid adenocarcinomas grade 1, 25 endometrioid adenocarcinomas grade 2, 20 endometrioid adenocarcinomas grade 3, 8 carcinosarcomas, 6 serous adenocarcinomas and 2 clear cell carcinomas. Clinical stagings were assessed based on the FIGO staging system as follows: 21 stage IA cancers, 44 stage IB cancers, 14 stage IC cancers, 3 stage IIA cancers, 9 stage IIB cancers, 14 stage IIIA cancers, 10 stage IIIC cancers, and 7 stage IVB cancers. The median age at the time of surgery was 56.98 years (range: 32-78 years) (Table I).

Anthropometric measurements. Each participant was also measured for her weight, standing height, and waist circumference at admission time. Body weight was measured with electronic scales to the nearest $0.1 \mathrm{~kg}$. Height was measured to nearest $0.1 \mathrm{~cm}$ using a stadiometer. Girth measurements, recorded to the nearest $0.1 \mathrm{~cm}$, were taken with a cloth tape. Waist circumference was measured at a level $2.5 \mathrm{~cm}$ above the umbilicus. Adiposity was estimated using body weight, BMI, and body surface area (BSA). BMI was computed as weight in kilograms divided by height in meters squared $\left(\mathrm{kg} / \mathrm{m}^{2}\right)$. We calculated BSA by using the Fujimoto formulae $\left(\mathrm{BSA}=0.008883 \times \mathrm{H}^{0.663} \mathrm{x} \mathrm{W}^{0.444}\right)$. In compliance with the Helsinki Declaration, the study protocol, purpose, and methodology were explained to subject, and they were informed of their right to withdraw at any time. Written informed consent for participation was obtained from all subjects. The study was performed under the supervision of an occupational health physician. The ethics committees of Okayama University approved the study protocol.
Table I. Patient and tumor characteristics (No. 1).

\begin{tabular}{lcc}
\hline Baseline characteristics & \multicolumn{2}{c}{ All patients } \\
\hline Age at diagnosis, years & Mean: 56.98; range: 32-78 \\
& Nos. & $(\%)$ \\
Stage & 21 & 17.2 \\
IA & 44 & 36.1 \\
IB & 14 & 11.5 \\
IC & 3 & 2.5 \\
IIA & 9 & 7.4 \\
IIB & 14 & 11.5 \\
IIIA & 10 & 8.1 \\
IIIC & 7 & 5.7 \\
IVB & & \\
Histology & & \\
Endometrioid adenocarcinoma & & \\
Grade 1 & 61 & 50 \\
Grade 2 & 25 & 20.5 \\
Grade 3 & 20 & 16.4 \\
Carcinosarcoma & 8 & 6.6 \\
Serous adenocarinoma & 6 & 4.9 \\
Clear cell carcinoma & 2 & 1.6 \\
\hline
\end{tabular}

Measurement of visceral and subcutaneous fat areas. We examined the volume of visceral fat areas (VFA) and subcutaneous fat areas (SFA) in one slice of a CT scan, using Fat Scan software (O-Gauge System, Tokyo, Japan). Several studies have revealed that the VFA shown from a single scan obtained at the level of the umbilicus (the level from L4 to L5) is highly correlated with the total visceral fat volume (15). Hence, we used a slice of a CT image at the umbilical level to measure VFA and SFA. Also, the total fat area (TFA) was determined as the sum of the SFA and VFA (Fig. 1).

Measurement of serum total cholesterol. The assay for serum total cholesterol (T.Cho) was carried out at the clinical chemistry laboratory at Okayama University Hospital. The upper limit of normal according to the manufacturer was $220 \mathrm{mg} / \mathrm{ml}$ for total cholesterol (T.Cho).

Statistical analysis. Statistical analyses were performed using the Mann-Whitney U test for comparisons with controls and one-factor ANOVA followed by Fisher's protected least significance difference test for all pairwise comparisons. The analyses were performed using the software package StatView version 5.0 (Abacus Concepts, Berkeley, CA). Differences were considered significant at $\mathrm{p}<0.05$.

\section{Results}

The most significant risk factors for endometrial cancer include unopposed estrogen, a sedentary lifestyle, and obesity (16). Endometrial cancer was the first cancer to be recognized as being related to obesity. We determined whether there was 
A
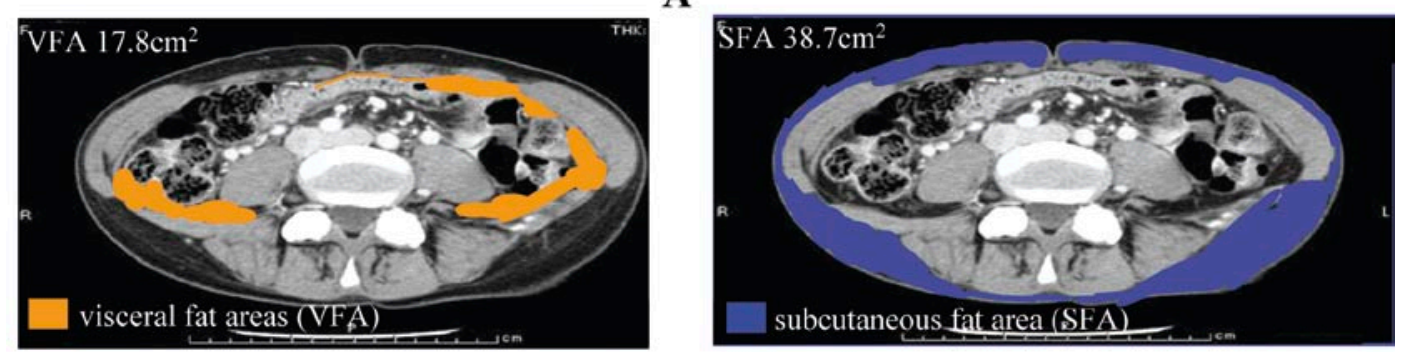

B
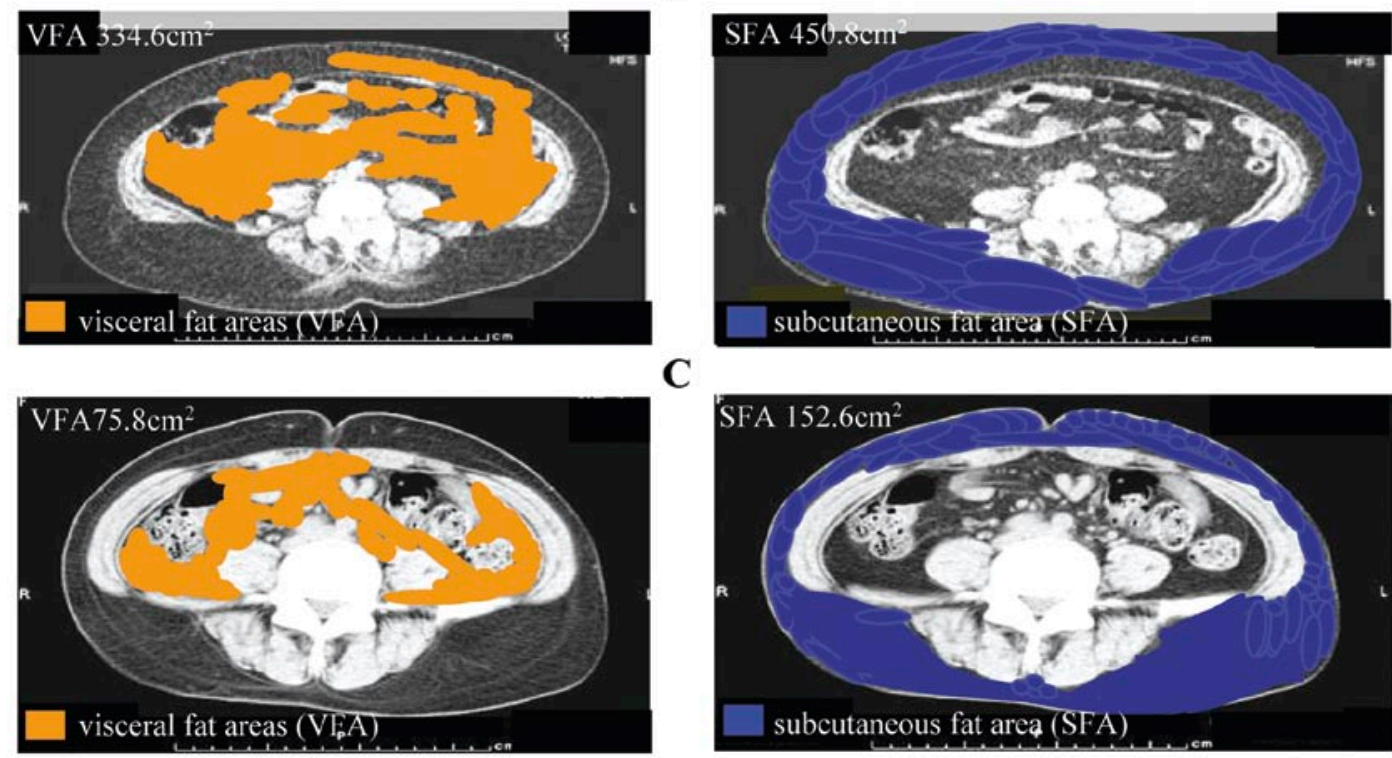

C

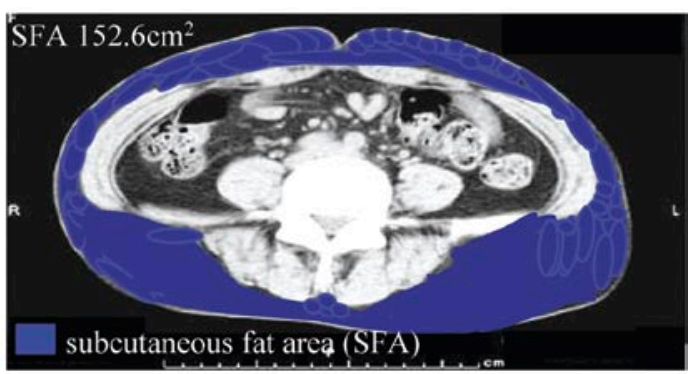

D
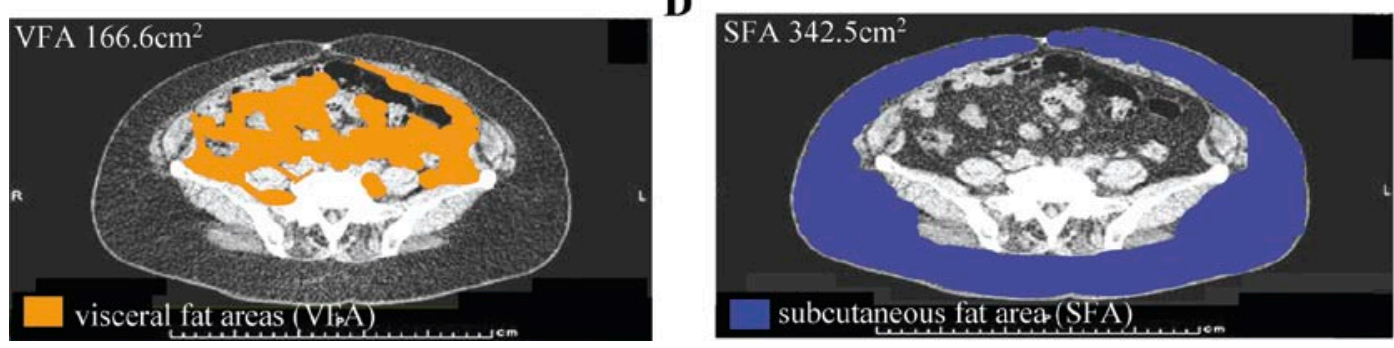

Figure 1. Measurement of the degree of the fat accumulation in adipose tissues in endometrial cancer. (A) Forty-five year-old with endometrial cancer stage IIIast, serous adenocarcinoma (T3aN0M0). Height $158.5 \mathrm{~cm}$, weight $48.5 \mathrm{~kg}$, body mass index (BMI) $19.31 \mathrm{~kg} / \mathrm{m}^{2}$, waist circumference $67 \mathrm{~cm}$, body surface area (BSA) $1.43 \mathrm{~m}^{2}$, subcutaneous and visceral fat area (TFA) $56.5 \mathrm{~cm}^{2}$, visceral fat area (VFA) $17.8 \mathrm{~cm}^{2}$, subcutaneous fat area (SFA) $38.7 \mathrm{~cm}$, and total cholesterol (T.Cho) $199 \mathrm{mg} / \mathrm{dl}$. (B) Sixty-five year-old with endometrial cancer stage Iast, endometrioid adenocarcinoma grade I (TIaN0M0). Height $156.5 \mathrm{~cm}$, weight $97.1 \mathrm{~kg}$, BMI $39.65 \mathrm{~kg} / \mathrm{m}^{2}$, waist circumference $120.0 \mathrm{~cm}$, BSA $1.93 \mathrm{~m}^{2}$, TFA $785.4 \mathrm{~cm}^{2}$, VFA $334.6 \mathrm{~cm}^{2}$, SFA $450.8 \mathrm{~cm}^{2}$, and T.Cho $225 \mathrm{mg} / \mathrm{dl}$. (C) Fifty-seven year-old with endometrial cancer stage IIIast, endometrioid adenocarcinoma grade 1 (T3aNOM0). Height $160.0 \mathrm{~cm}$, weight $56.5 \mathrm{~kg}$, BMI $22.07 \mathrm{~kg} / \mathrm{m}^{2}$, waist circumference $71.5 \mathrm{~cm}$, BSA1.54 m², TFA $228.4 \mathrm{~cm}^{2}$, VFA $75.8 \mathrm{~cm}^{2}$, SFA $152.6 \mathrm{~cm}^{2}$, and T.Cho $218 \mathrm{mg} / \mathrm{dl}$. (D) Sixty-eight year-old with endometrial cancer stage IIbst, serous adenocarcinoma (T2bNOM0). Height $145.0 \mathrm{~cm}$, weight $61.9 \mathrm{~kg}$, BMI $29.44 \mathrm{~kg} / \mathrm{m}^{2}$, waist circumference $101.5 \mathrm{~cm}$, BSA $1.50 \mathrm{~m}^{2}$, TFA $508.6 \mathrm{~cm}^{2}$, VFA $166.6 \mathrm{~cm}^{2}$, SFA $342.5 \mathrm{~cm}^{2}$, and T.Cho $158 \mathrm{mg} / \mathrm{dl}$.

an association between the distribution of fat accumulation in adipose tissue and obesity-related biological parameters in endometrial cancer. The height, weight, BMI, waist, BSA, VFA, SFA, TFA, and T.Cho are listed in Table II. The median of height, weight, BMI, waist, BSA, VFA, SFA, TFA, and T.Cho were $154.16 \mathrm{~cm}, 58.74 \mathrm{~kg}, 24.70 \mathrm{~kg} / \mathrm{m}^{2}, 83.47 \mathrm{~cm}$, $1.52 \mathrm{~m}^{2}, 88.27 \mathrm{~cm}^{2}, 206.91 \mathrm{~cm}^{2}, 294.43 \mathrm{~cm}^{2}$, and $202.70 \mathrm{mg} / \mathrm{dl}$, respectively.

A number of investigators have explored the role of obesity in the development of endometrial cancer, primarily using measurement of body weight and indices of relative weight as an indicator of overall adiposity. However, there are no studies that describe the fat accumulation in adipose tissue in endometrial cancer. We examined the association between the fat accumulation in adipose tissues (TFA, VFA, SFA) and obesity-related biological parameters (weight, BMI, waist, and BSA). As shown in Fig. 2, the fat accumulation in adipose tissues (TFA, VFA, SFA) was plotted in relation to weight. TFA was most strongly correlated with weight $(\mathrm{r}=0.873, \mathrm{p}<0.001)$, while VFA and SFA were less closely correlated with weight $(\mathrm{r}=0.750, \mathrm{p}<0.001 ; \mathrm{r}=0.857, \mathrm{p}<0.001)$. BMI, waist, and BSA were also closely associated with the fat accumulation in adipose tissues (TFA, VFA, SFA) $(\mathrm{r}=0.907, \mathrm{p}<0.001 ; \mathrm{r}=0.743, \mathrm{p}<0.001 ; \mathrm{r}=0.895, \mathrm{p}<0.001$; 

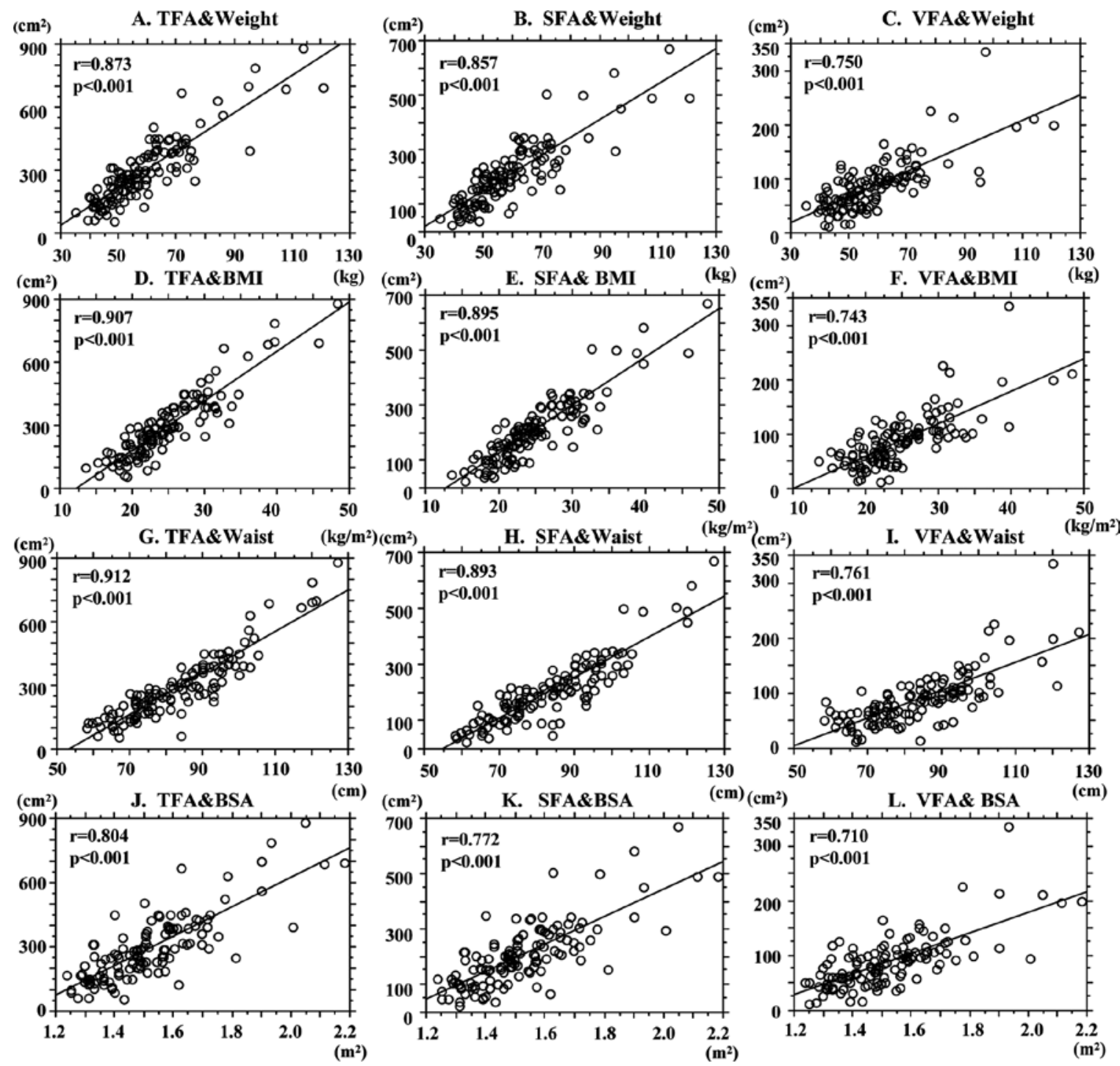

Figure 2. (A) Correlations between subcutaneous and visceral fat area (TFA) and weight in the subjects investigated. (B) Correlations between subcutaneous fat area (SFA) and weight in the subjects investigated. (C) Correlations between visceral fat area (VFA) and weight in the subjects investigated. (D) Correlations between TFA and body mass index (BMI) in the subjects investigated. (E) Correlations between SFA and BMI in the subjects investigated. (F) Correlations between VFA and BMI in the subjects investigated. (G) Correlations between TFA and waist circumference in the subjects investigated. (H) Correlations between SFA and waist circumference in the subjects investigated. (I) Correlations between VFA and waist circumference in the subjects investigated. (J) Correlations between TFA and body surface area (BSA) in the subjects investigated. (K) Correlations between SFA and BSA in the subjects investigated. (L) Correlations between VFA and BSA in the subjects investigated.

$\mathrm{r}=0.912, \mathrm{p}<0.001 ; \mathrm{r}=0.761, \mathrm{p}<0.001 ; \mathrm{r}=0.893, \mathrm{p}<0.001 ;$ $\mathrm{r}=0.804, \mathrm{p}<0.001 ; \mathrm{r}=0.710, \mathrm{p}<0.001$; and $\mathrm{r}=0.772, \mathrm{p}<0.001$ ). Interestingly, the fat accumulation in adipose tissue was related to the biological parameters, such as weight, BMI, waist, and BSA in endometrial cancer. Furthermore, the TFA in the adipose tissue was most closely associated with the development of endometrial cancer than SFA or VFA.

Most epidemiologic studies have considered all types of endometrial cancers as a single entity, rather than analyzing them as different histological types. Instead, we chose to explore the associations between the distribution of obesityrelated factors and various histological types of endometrial cancer. Patients with type I endometrial cancer showed an increase in obesity-related biological parameters such as weight $(p=0.011)$, BMI $(p=0.006)$, waist circumference $(\mathrm{p}=0.038)$, BSA $(\mathrm{p}=0.016)$, SFA $(\mathrm{p}=0.005)$, TFA $(\mathrm{p}=0.006)$, and T.Cho $(\mathrm{P}=0.010)$ than the patients with type II endometrial cancer where no associations were detected for age, height, or VFA. In particular, the SFA was most strongly correlated with obesity-related biological parameters of type I endometrial cancer (Mann-Whitney U test, $\mathrm{p}<0.05$ ) (Table III). Furthermore, we also examined whether there was any correlation with the various stages of endometrial cancer in relation to the biological parameters. However, we observed no association between the various stages and obesity-related parameters in type I endometrial cancer (Table IV).

\section{Discussion}

The effect of obesity on endometrial cancer risk has been of interest for decades. Several studies have explored the role of obesity in the development of endometrial cancer, primarily using measurements of body weight and indices of relative weight as assessments of overall adiposity. These investigators 
Table II. Patient and tumor characteristics (No. 2).

\begin{tabular}{|c|c|c|}
\hline & Nos. & $(\%)$ \\
\hline \multicolumn{3}{|l|}{ Height (cm) } \\
\hline$<145.0$ & 8 & 6.6 \\
\hline $145.0-149.9$ & 18 & 14.8 \\
\hline $150.0-154.9$ & 36 & 29.5 \\
\hline $155.0-159.9$ & 38 & 31.1 \\
\hline$>160.0$ & 22 & 18 \\
\hline \multicolumn{3}{|l|}{ Weight (kg) } \\
\hline$<50.0$ & 36 & 29.5 \\
\hline $50.0-59.9$ & 39 & 32 \\
\hline $60.0-69.9$ & 24 & 19.7 \\
\hline $70.0-79.9$ & 15 & 12.3 \\
\hline$>80.0$ & 8 & 6.5 \\
\hline \multicolumn{3}{|l|}{ BMI $\left(\mathrm{kg} / \mathrm{m}^{2}\right)$} \\
\hline$<18.5$ & 12 & 9.8 \\
\hline $18.5-24.9$ & 65 & 53.4 \\
\hline $25.0-29.9$ & 25 & 20.5 \\
\hline $30.0-34.9$ & 14 & 11.5 \\
\hline$>35.0$ & 6 & 4.8 \\
\hline \multicolumn{3}{|l|}{ Waist (cm) } \\
\hline$<70.0$ & 19 & 15.6 \\
\hline $70.0-79.9$ & 33 & 27 \\
\hline $80.0-89.9$ & 27 & 22.1 \\
\hline $90.0-99.9$ & 27 & 22.1 \\
\hline$>100.0$ & 16 & 13.2 \\
\hline \multicolumn{3}{|l|}{$\operatorname{BSA}\left(\mathrm{cm}^{2}\right)$} \\
\hline$<1.40$ & 33 & 27 \\
\hline $1.40-1.49$ & 30 & 24.6 \\
\hline $1.50-1.59$ & 29 & 23.7 \\
\hline $1.60-1.69$ & 16 & 13.2 \\
\hline$>1.7$ & 14 & 11.5 \\
\hline \multicolumn{3}{|l|}{$\operatorname{VFA}\left(\mathrm{cm}^{2}\right)$} \\
\hline$<50.0$ & 24 & 19.7 \\
\hline $50.0-99.9$ & 58 & 47.6 \\
\hline $100.0-149.9$ & 31 & 25.4 \\
\hline 150.0-199.9 & 5 & 4.1 \\
\hline$>200.0$ & 4 & 3.2 \\
\hline \multicolumn{3}{|l|}{$\operatorname{SFA}\left(\mathrm{cm}^{2}\right)$} \\
\hline$<100.0$ & 22 & 18 \\
\hline $100.0-199.9$ & 42 & 34.5 \\
\hline 200.0-299.9 & 36 & 29.5 \\
\hline $300.0-399.9$ & 15 & 12.3 \\
\hline$>400.0$ & 7 & 5.7 \\
\hline \multicolumn{3}{|c|}{ TFA (VFA+SFA) $\left(\mathrm{cm}^{2}\right)$} \\
\hline$<150.0$ & 21 & 17.2 \\
\hline $150.0-249.9$ & 29 & 23.7 \\
\hline $250.0-349.9$ & 34 & 27.9 \\
\hline $350.0-449.9$ & 23 & 18.9 \\
\hline$>450.0$ & 15 & 12.3 \\
\hline \multicolumn{3}{|l|}{ T.Cho (mg/dl) } \\
\hline$<160.0$ & 17 & 14 \\
\hline $160.0-189.9$ & 27 & 22.1 \\
\hline $190.0-219.9$ & 44 & 36.1 \\
\hline $220.0-249.9$ & 22 & 18 \\
\hline$>250.0$ & 12 & 9.8 \\
\hline
\end{tabular}

BMI, body mass index; BSA, body surface area; VFA, visceral fat area; SFA, subcutaneous fat area; TFA, total fat area; T.Cho, total cholesterol.
Table III. Association between type I/II and clinicopathological factors in endometrial cancer.

\begin{tabular}{|c|c|c|}
\hline Variables & Mean \pm SE & p-value \\
\hline Age (years) & & 0.331 \\
\hline Type I & $56.33 \pm 11.90$ & \\
\hline Type II & $58.14 \pm 8.03$ & \\
\hline Height (cm) & & 0.45 \\
\hline Type I & $153.93 \pm 6.68$ & \\
\hline Type II & $154.72 \pm 4.53$ & \\
\hline Weight (kg) & & $0.011^{\mathrm{a}}$ \\
\hline Type I & $60.57 \pm 16.54$ & \\
\hline Type II & $54.35 \pm 9.71$ & \\
\hline BMI $\left(\mathrm{kg} / \mathrm{m}^{2}\right)$ & & $0.006^{\mathrm{a}}$ \\
\hline Type I & $25.52 \pm 6.37$ & \\
\hline Type II & $22.74 \pm 4.17$ & \\
\hline Waist (cm) & & $0.038^{\mathrm{a}}$ \\
\hline Type I & $85.03 \pm 15.15$ & \\
\hline Type II & $79.75 \pm 11.48$ & \\
\hline $\operatorname{BSA}\left(m^{2}\right)$ & & $0.016^{\mathrm{a}}$ \\
\hline Type I & $1.54 \pm 0.19$ & \\
\hline Type II & $1.47 \pm 0.12$ & \\
\hline $\operatorname{VFA}\left(\mathrm{cm}^{2}\right)$ & & 0.309 \\
\hline Type I & $92.37 \pm 52.36$ & \\
\hline Type II & $78.47 \pm 73.78$ & \\
\hline $\mathrm{SFA}\left(\mathrm{cm}^{2}\right)$ & & $0.005^{\mathrm{a}}$ \\
\hline Type I & $221.85 \pm 126.92$ & \\
\hline Type II & $171.21 \pm 73.78$ & \\
\hline TFA $(\mathrm{VFA}+\mathrm{SFA})\left(\mathrm{cm}^{2}\right)$ & & $0.006^{\mathrm{a}}$ \\
\hline Type I & $314.05 \pm 168.46$ & \\
\hline Type II & $247.56 \pm 97.92$ & \\
\hline T.Cho (mg/dl) & & $0.010^{\mathrm{a}}$ \\
\hline Type I & $208.27 \pm 38.37$ & \\
\hline Type II & $189.42 \pm 31.62$ & \\
\hline
\end{tabular}

${ }^{a}$ Mann-Whitney U test; BMI, body mass index; BSA, body surface area; VFA, visceral fat area; SFA, subcutaneous fat area; TFA, total fat area; T.Cho, total cholesterol. Type I $(n=86)$, Type II $(n=36)$.

have reported that overall adiposity is a strong risk factor for endometrial cancer, with risk estimates ranging from 10 (17).

In particular, many obese Japanese subjects have a mild degree of adiposity compared with the problem in Europe and the United States. However, Japanese with even mild obesity tend to have obesity-related complications, thus establishing criteria that are appropriate for use in diagnosing obesity disease in Japanese subjects is a priority. The WHO and National Institute of Health in the US (NIH) have defined obesity as BMI $\geq 30 \mathrm{~kg} / \mathrm{m}^{2}$, but in Japan, the percentage of the population with such a BMI is no more than 3.0 , so it is not practical to apply these Western criteria without any modifications to the Japanese. In this study, the percentage of patients with a BMI $\geq 30 \mathrm{~kg} / \mathrm{m}^{2}$ was $16.3 \%$. Furthermore, the percentage of patients with a BMI $\geq 25 \mathrm{~kg} / \mathrm{m}^{2}$ was $36.8 \%$. Interestingly, patients with endometrial cancer were found to 
Table IV. Association between stage and clinicopathological factors in type I endometrial cancer.

\begin{tabular}{|c|c|c|}
\hline Variables & $\begin{array}{c}\text { Type I } \\
\text { Stage I/II } \\
n=70\end{array}$ & $\begin{array}{c}\text { Type } \mathrm{I}^{\mathrm{a}} \\
\text { Stage III/IV } \\
\mathrm{n}=16\end{array}$ \\
\hline Age (years) & $56.57 \pm 12.21$ & $\begin{array}{c}55.25 \pm 10.38 \\
\mathrm{p}=0.690\end{array}$ \\
\hline Height $(\mathrm{cm})$ & $153.7 \pm 6.53$ & $\begin{array}{c}154.94 \pm 7.45 \\
p=0.506\end{array}$ \\
\hline Weight (kg) & $60.9 \pm 16.93$ & $\begin{array}{c}59.12 \pm 15.09 \\
\mathrm{p}=0.700\end{array}$ \\
\hline BMI & $25.71 \pm 6.48$ & $\begin{array}{c}24.64 \pm 5.97 \\
p=0.547\end{array}$ \\
\hline Waist (cm) & $84.97 \pm 14.90$ & $\begin{array}{c}85.31 \pm 14.90 \\
\mathrm{p}=0.938\end{array}$ \\
\hline $\operatorname{BSA}\left(m^{2}\right)$ & $1.54 \pm 0.20$ & $\begin{array}{c}1.53 \pm 0.19 \\
p=0.856\end{array}$ \\
\hline $\operatorname{VFA}\left(\mathrm{cm}^{2}\right)$ & $93.62 \pm 53.11$ & $\begin{array}{c}86.90 \pm 50.16 \\
p=0.646\end{array}$ \\
\hline $\mathrm{SFA}\left(\mathrm{cm}^{2}\right)$ & $222.15 \pm 127.34$ & $\begin{array}{c}220.58 \pm 129.18 \\
p=0.965\end{array}$ \\
\hline TFA $(\mathrm{VFA}+\mathrm{SFA})\left(\mathrm{cm}^{2}\right)$ & $315.84 \pm 169.12$ & $\begin{array}{c}306.21 \pm 170.79 \\
p=0.838\end{array}$ \\
\hline T.Cho $(\mathrm{mg} / \mathrm{ml})$ & $210.13 \pm 40.06$ & $\begin{array}{c}200.12 \pm 29.55 \\
p=0.349\end{array}$ \\
\hline
\end{tabular}

${ }^{a}$ Mann-Whitney U test; BSA, body surface area; VFA, visceral fat area; SFA, subcutaneous fat area; TFA, total fat area; T.Cho, total cholesterol.

have a statistically significant association with obesity than the general population in Japan.

In this study, we used a slice of a CT image at the umbilicus and separately quantified the visceral fat area (VFA), subcutaneous fat area (SFA), and total fat area (TFA) in endometrial cancer patients. Visceral fat is defined as intra-abdominal fat found by parietal peritoneum or transversalis fascia, excluding the vertebral column and paraspinal muscles. The subcutaneous fat is fat superficial to the abdominal and back muscles. SFA is calculated by subtracting the intra-abdominal fat area from the total fat area. The TFA and VFA in the older group were significantly larger than those in the younger group. The same trend was reported for BMI in the general Japanese population. Several experimental studies suggest that the visceral adiposity, the fat accumulation in visceral adipose tissue, is a strong risk factor for obesity-related metabolic syndrome, and is also important in understanding metabolic derangement, such as insulin resistance and dyslipidemia in the normal-weight population. Increased VFA is associated with the development of colon adenoma in Japanese patients (18). The visceral adipocytes increased the obesity-related factors such as adiponectin, interleukin-6, and angiotensinogen more than the subcutaneous fat. On the other hand, the subcutaneous adipocytes provide more leptin than the visceral adipocytes (19). The subcutaneous fat depot has the highest secretion rate due to enlarged cell size and increased expression of the leptin gene (11). However, SFA has not been reported to be associated with the development of several carcinomas. In the current study, we found that the fat accumulation in adipose tissues was associated with obesity-related biological parameters such as weight, BMI, waist circumference, and BSA. Taken together, these findings indicate that the fat accumulation in adipose tissues could be an important factor for the development of endometrial cancer.

Cholesterol is involved in several metabolic pathways leading to estrogen and is the major substrate leading to steroid hormone synthesis including estrogens (20). The endogenous hormone metabolism including sex steroids, insulin and insulin-like growth factors associated with unopposed estrogenic stimulation, such as obesity, are also believed to be primarily related to the development of type I endometrial cancer (16). In the present study, we explore the associations between the fat accumulation in adipose tissue distribution and various histological types of endometrial cancer. Patients with type I endometrial cancer were found to have a statistically significant increase in biological parameters such as weight, BMI, waist circumference, BSA, SFA, TFA, and T.Cho than the patients with type II endometrial cancer, whereas no associations were detected for age, height, or VFA. Therefore, subcutaneous adipose tissue is the primary obesity-related factor associated with the development of type I endometrial cancer. Furthermore, subcutaneous fat accumulation in adipose tissue is a strong risk factor for the development of type I endometrial cancer. The large number of patients analyzed supports the strength of our data and further confirmation by an additional study should reinforce our findings.

In summary, we demonstrated that patients with type I endometrial cancer have a statistically significant association with obesity-related biological parameters than those with type II endometrial cancer.

\section{References}

1. Friedenreich C, Cust A, Lahmann PH, Steindorf K, BoutronRuault MC, Clavel-Chapelon F, Mesrine S, et al: Anthropometric factors and risk of endometrial cancer: the European prospective investigation into cancer and nutrition. Cancer Causes Control 18: 399-413, 2007.

2. Setiawan VW, Pike MC, Kolonel LN, Nomura AM, Goodman MT and Henderson BE: Racial/ethnic differences in endometrial cancer risk: the multiethnic cohort study. Am J Epidemiol 165: 262-270, 2007.

3. Sherman ME: Theories of endometrial carcinogenesis: a multidisciplinary approach. Mod Pathol 13: 295-308, 2000.

4. Bokhman JV: Two pathogenetic types of endometrial carcinoma. Gynecol Oncol 15: 10-17, 1983

5. Annual Report of Oncology Committee of Japan Society of Obstetrics and Gynecology, Tokyo, 2010 (in Japanese).

6. Yanai M, Kon A, Kumasaka K and Kawano K: Body mass index variations by age and sex, and prevalence of overweight in Japanese adults. Int J Obes Relat Metab Disord 21: 484-488, 1997.

7. Seidell JC, Verschuren WM and Kromhout D: Prevalence and trends of obesity in The Netherlands 1987-1991. Int J Obes Relat Metab Disord 19: 924-927, 1995. 
8. Examination committee of criteria for 'obesity disease' in Japan, Japan Society for the Study of Obesity. Circ J 66: 987-992, 2002.

9. Collaborative study of Japan Society for the Study of Obesity and Japanese Ministry of Health and Welfare, Epidemiological studies on obesity. Research report in 1996; Japanese Ministry of Health and Welfare, Tokyo, 1997 (in Japanese).

10. Ishikawa M, Kitayama J, Yamauchi T, Kadowaki T, Maki T, Miyato $\mathrm{H}$, Yamashita $\mathrm{H}$, et al: Adiponectin inhibits the growth and peritoneal metastasis of gastric cancer through its specific membrane receptors AdipoR1 and AdipoR2. Cancer Sci 98: 1120-1127, 2007

11. Yin N, Wang D, Zhang H, Yi X, Sun X, Shi B, Wu H, et al: Molecular mechanisms involved in the growth stimulation of breast cancer cells by leptin. Cancer Res 64: 5870-5875, 2004.

12. Iannucci CV, Capoccia D, Calabria M and Leonetti F: Metabolic syndrome and adipose tissue: new clinical aspects and therapeutic targets. Curr Pharm Des 13: 2148-2168, 2007.

13. Giovannucci E, Ascherio A, Rimm EB, Colditz GA, Stampfer MJ and Willett WC: Physical activity, obesity, and risk for colon cancer and adenoma in men. Ann Intern Med 122: 327-334, 1995.

14. Schoen RE, Tangen CM, Kuller LH, Burke GL, Cushman M, Tracy RP, Dobs A, et al: Increased blood glucose and insulin, body size, and incident colorectal cancer. J Natl Cancer Inst 91 $1147-1154,1999$
15. Kvist H, Chowdhury B, Sjöström L, Tylén U and Cederblad A: Adipose tissue volume determination in males by computed tomography and 40K. Int J Obes 12: 249-266, 1988.

16. Kaaks R, Lukanova A and Kurzer MS: Obesity, endogenous hormones, and endometrial cancer risk: a synthetic review. Cancer Epidemiol Biomarkers Prev 11: 1531-1543, 2002.

17. Folsom AR, Kaye SA, Potter JD and Prineas RJ: Association of incident carcinoma of the endometrium with body weight and fat distribution in older women: early findings of the Iowa Women's Health Study. Cancer Res 49: 6828-6831, 1989.

18. Otake S, Takeda H, Suzuki Y, Fukui T, Watanabe S, Ishihama K, Saito T, et al: Association of visceral fat accumulation and plasma adiponectin with colorectal adenoma: evidence for participation of insulin resistance. Clin Cancer Res 11: 3642-3646, 2005.

19. Wajchenberg BL: Subcutaneous and visceral adipose tissue: their relation to the metabolic syndrome. Endocr Rev 21: 697-738, 2000

20. Speroff L and Fritz MA: Clinical Gynecologic Endocrinology and Infertility. Lippincott Williams \& Wilkins, Baltimore, 2004. 